Published in final edited form as:

Curr Opin Neurobiol. 2006 December ; 16(6): 710-715. doi:10.1016/j.conb.2006.09.002.

\title{
The Role of Acetylcholine in Learning and Memory
}

\author{
Michael E. Hasselmo \\ Center for Memory and Brain, Boston University, 2 Cummington St., Boston, MA 02215, \\ hasselmo@bu.edu, 617-353-1397
}

\section{Summary}

Pharmacological data clearly indicate that both muscarinic and nicotinic acetylcholine receptors play a role in encoding of new memories. Localized lesions and antagonist infusions demonstrate the anatomical locus of these cholinergic effects, and computational modeling links the function of cholinergic modulation to specific cellular effects within these regions. Acetylcholine may enhance encoding by increasing the strength of afferent input relative to feedback, by contributing to theta rhythm oscillations, by activating intrinsic mechanisms for persistent spiking, and by increasing the modification of synapses. These effects may enhance different types of encoding in different cortical structures. In particular, the effects in entorhinal and perirhinal cortex and hippocampus may be important for encoding of new episodic memories.

\section{Introduction}

Pharmacological studies in human subjects conclusively demonstrate that blockade of muscarinic cholinergic receptors by drugs such as scopolamine impairs the encoding of new memories, but not the retrieval of previously stored memories [1,2], and impairs working memory for some stimuli [3]. Conversely, drugs which activate nicotinic receptors enhance the encoding of new information [4,5]. This article will discuss how the specific cellular effects of acetylcholine within cortical structures could underlie the role of acetylcholine in encoding of new memories.

\section{Anatomical location of the cholinergic effect}

Localized infusions of cholinergic antagonists into specific anatomical structures demonstrate the importance of cholinergic receptors for particular aspects of memory tasks. Localized infusions of scopolamine into parahippocampal structures demonstrate a role of cholinergic receptors in these structures for the encoding of information for subsequent recognition in both monkeys [6] and rats [7]. These studies used tasks in which animals are exposed to one or multiple sample stimuli during encoding, and are subsequently tested on their delayed recognition of these sample stimuli and rejection of other stimuli which were not presented during the sample phase. Local infusions into perirhinal cortex in monkeys impair encoding for subsequent recognition, whereas infusions into dentate gyrus or inferotemporal cortex do not [6]. Local infusions into perirhinal cortex in rats impair object recognition, as measured by exploration time, but do not impair spatial alternation, suggesting task specificity [7].

Local application of cholinergic antagonists into other regions also cause selective impairments. Infusions of scopolamine into the hippocampus impair spatial encoding [8] and infusions into the medial septum impair spatial learning and reduce acetylcholine release in the hippocampus [9]. Infusions of carbachol into the medial septum, which increase levels of hippocampal acetylcholine, also impair memory $[9,10]$, possibly by interfering with consolidation [10]. Infusions of scopolamine into region CA3 cause selective impairments of encoding but not retrieval in the Hebb-Williams maze [11]. 
Anatomical localization of cholinergic function can also be studied with localized injections of saporin conjugated with antibodies to cholinergic neurons. Retrograde transport of the saporin results in a selective lesion of cholinergic neurons innervating the structure that was injected. Selective lesions of the entorhinal cortex in rats cause impairments in delayed nonmatch to sample for novel but not familiar odor stimuli [12]. Similarly, cholinergic lesions of the perirhinal cortex in monkeys cause impairments in visual delayed match to sample performance [13]. Selective cholinergic lesions of the medial septum do not cause impairments as strong as complete medial septal lesions, suggesting that the role of this cholinergic innervation in spatial memory encoding can be substituted by GABAergic innervation from the medial septum [14].

The anatomical localization studies allow behavioral effects to be linked to specific cellular effects of acetylcholine described using intracellular recording techniques in slice preparations. Computational models demonstrate how the cellular mechanisms of these effects could enhance encoding of memories. These cellular mechanisms include: 1.) enhancement of the influence of afferent input relative to excitatory feedback; 2.) regulation of inhibition and theta rhythm oscillations, 3.) enhancement of persistent spiking for active maintenance, and 4.) enhancement of synaptic modification.

\section{Enhancement of afferent input relative to excitatory feedback}

As summarized in Figure 1, acetylcholine may enhance the encoding of memory by enhancing the influence of feedforward afferent input to the cortex, making cortical circuits respond to features of sensory stimuli, while decreasing excitatory feedback activity mediating retrieval. This change in dynamics results from effects including nicotinic enhancement of excitatory afferent input, and muscarinic presynaptic inhibition of excitatory feedback.

\section{Nicotinic enhancement of afferent input}

The behavioral evidence for nicotinic enhancement of memory function may partly result from enhancement of afferent input to cortical structures where memories are encoded. For example, nicotinic enhancement of excitatory synaptic transmission has been shown for the afferent input to hippocampal region CA3 from entorhinal cortex [15] and from the dentate gyrus [16], but not for excitatory feedback within CA3. Similarly, in thalamocortical slice preparations of somatosensory cortex [17], activation of nicotinic receptors enhances thalamic input but not excitatory feedback synapses. Nicotinic enhancement of glutamatergic transmission has also been shown at the medial dorsal thalamic input to prefrontal cortex [18]. These effects could enhance the influence of sensory input on cortical spiking activity during encoding, particularly since they would be accompanied by enhancement of the spiking response to afferent input due to muscarinic depolarization of pyramidal cells and reductions in spike frequency accommodation [reviewed in [2,19]].

\section{Muscarinic presynaptic inhibition}

Acetylcholine may also enhance encoding via muscarinic presynaptic inhibition of excitatory feedback synapses within cortical circuits [2]. Modeling shows that the reduction of excitatory feedback enhances encoding by reducing interference from previous retrieval [20]. In the piriform cortex, cholinergic modulation causes selective presynaptic inhibition of excitatory feedback potentials, while having a much weaker effect on afferent synaptic potentials [21]. In region CA3 of hippocampus, muscarinic receptors suppress excitatory transmission at recurrent connections in stratum radiatum [22,23], but not at afferent synapses in stratum lucidum [22] or stratum lacunosum moleculare (Kremin and Hasselmo, unpublished data). Acetylcholine suppresses excitatory potentials in stratum radiatum of region CA1 [20,24], but not as much in stratum lacunosum-moleculare (SLM), where entorhinal cortex layer III input 
terminates [20]. Presynaptic inhibition appears to be stronger for synapses with AMPA receptors versus silent synapses in hippocampus [25] consistent with physiological evidence that presynaptic inhibition is stronger for recently potentiated synapses in piriform cortex [26]. Modeling demonstrates that this selectivity would enhance self-organization of new representations for afferent input [26], which has been shown experimentally [27]. Consistent with the models of cholinergic presynaptic inhibition in hippocampus, local infusion of cholinergic antagonists in hippocampus causes an increase in background spiking activity in unit recordings [28]. Presynaptic inhibition also appears in areas such as the subiculum [29].

These effects could alter cortical functional dynamics as acetylcholine levels change during waking and sleep [30]. High cholinergic levels during waking suppress feedback, providing dominant feedforward effects appropriate for encoding, and reducing the influence of hippocampus on entorhinal cortex [31]. In contrast, lower acetylcholine levels during slow wave sleep remove the presynaptic inhibition, resulting in dominant feedback effects appropriate for consolidation, and resulting in greater spiking activity and evoked potentials in deep layers of entorhinal cortex [31]. This predicts that consolidation of memory should be impaired by increases in acetylcholine levels during consolidation. This hypothesis is supported by impairments of consolidation caused by cholinergic infusions into medial septum after training in rats [10] and effects of the acetylcholinesterase blocker physostigmine on consolidation in humans [32]. Effects in neocortical structures are consistent with this functional framework, as cholinergic modulation causes presynaptic inhibition of feedback synapses from higher order somatosensory cortex, while having less effect on synaptic potentials elicited in layer IV [33]. Similarly, acetylcholine suppresses intracortical synaptic potentials but not thalamocortical input in the auditory cortex [34], and primary visual cortex [35].

\section{Modulation of inhibition and theta rhythm oscillations}

Acetylcholine may also enhance encoding through its role in increasing theta rhythm oscillations within the hippocampal formation [36,37]. Encoding is enhanced when stimuli are presented during periods of theta rhythmicity [38]. Modeling demonstrates how performance in memory tasks can be enhanced by changes in encoding and retrieval dynamics within each cycle of the theta rhythm [39], as shown in Figure 2. Theta rhythm is blocked by combined lesions of the cholinergic and GABAergic input from the medial septum [40]. Cholinergic neurons show theta rhythmic firing, which could provide rhythmic modulation of neuronal function in the hippocampus [41].

Interneurons play an important role in theta rhythm [42]. Cholinergic modulation directly depolarizes many hippocampal interneurons [43-45], which could enhance their activity during theta rhythm. Muscarinic receptors also reduce release of GABA [46]. This effect appears paradoxical, but computational modeling demonstrates that these combined effects reduce background activity, while heightening the response to suprathreshold sensory stimuli [19]. Cholinergic modulation also increases the rhythmicity of some interneurons [43]. This cholinergic regulation of interneuron rhythmicity could contribute to regulating the encoding and retrieval dynamics of the hippocampus, as shown in Figure 2. In the hippocampus, muscarinic receptors selectively depolarize oriens lacunosum-moleculare (O-LM) interneurons, but not non-OLM cells [47]. This could provide separate rhythmic timing of dendritic and somatic inhibition which could enhance separation of encoding and retrieval dynamics during theta rhythm oscillations [39,48].

\section{Enhancement of persistent spiking}

Acetylcholine has been demonstrated to enhance the persistent spiking of individual cortical neurons, which could provide a mechanism for active maintenance of novel information. This 
effect has been shown in entorhinal cortex [49], as well as other regions. As illustrated in Figure 3 , in standard control conditions, entorhinal neurons will respond to an intracellular depolarizing current injection by generating spiking activity during the current injection, but will terminate spiking after the end of current injection. In contrast, during perfusion with the cholinergic agonist carbachol, neurons respond to the same magnitude and duration of depolarizing current injection with an increased number of spikes, and when the current injection ends, they persist in spiking activity for an extended period of many seconds or even minutes $[49,50]$. This effect has also been described in other areas including perirhinal cortex [Giocomo, Tahvildari and Hasselmo, unpublished data] and prefrontal cortex [51].

This persistent spiking provides an excellent mechanism for active maintenance of novel information both for short-term working memory and for encoding of information into longterm memory. Detailed computational simulations of the entorhinal cortex [52] demonstrate how the cholinergic activation of intrinsic mechanisms for persistent spiking could underlie spiking activity during the delay period of delayed matching tasks in both rats [53] and monkeys [54], as well as phenomena such as match and non-match enhancement and suppression which occur during these tasks. Modeling demonstrates how cholinergic modulation activates a nonspecific cation current which causes a regenerative cycle in which spiking causes voltagesensitive calcium influx which further activates the non-specific cation current, causing persistent spiking. Modeling also demonstrates cellular mechanisms for the neurons in deep layers of entorhinal cortex which maintain graded firing frequencies for an extended period [50].

Modeling demonstrates how these intrinsic mechanisms for persistent firing could allow working memory for novel stimuli, for which synaptic connectivity has not previously been modified [12]. Consistent with this, scopolamine reduces parahippocampal fMRI activity observed during the delay period of a delayed match to sample task [55]. Loss of this persistent activity could underlie the impairment of delayed matching function in humans caused by scopolamine [3], as well as the impairments of encoding observed with localized infusions of scopolamine [6]. This hypothesis is also consistent with evidence that medial temporal lesions selectively impair working memory for new conjunctions of stimuli and complex nonverbalizable visual stimuli [56].

\section{Cholinergic enhancement of long-term potentiation}

Obviously, acetylcholine could also enhance encoding by enhancing long-term potentiation. Acetylcholine enhances LTP in many areas, including the hippocampus [57,58], entorhinal cortex [59] and piriform cortex [60]. In region CA1, induction of LTP depends on phase relative to spontaneous oscillatory activity [57]. Stimulation of the medial septum enhances LTP induction in vivo [61] and scopolamine blocks the LTP enhancement associated with medial septal activity [62]. Recent studies also demonstrate nicotinic enhancement of long-term potentiation [4].

\section{Conclusions}

In summary, there is increasing convergence of research on the role of acetylcholine in learning and memory. Top-down behavioral approaches have become more focused in using anatomically localized manipulations of cholinergic modulation. Bottom up cellular data from brain slice physiology can be linked to behavior by use of detailed computational models. Future work should combine local pharmacological manipulations with physiological recording in structures such as entorhinal cortex, to test whether cholinergic antagonists block persistent spiking activity and enhance feedback effects. In addition, studies should explore 
the role of cholinergic modulation in regulating the timing of action potentials relative to theta rhythm oscillations.

\section{Acknowledgements}

This work supported by the National Institutes of Health, grant numbers MH60013, MH61492 and DA16454 (as part of the program for Collaborative Research in Computational Neuroscience) and by National Science Foundation Science of Learning Center SBE 0354378. Thanks to Lisa Giocomo and Eric Zilli for comments. The author has no conflict of interest.

\section{References}

1. Atri A, Sherman S, Norman KA, Kirchhoff BA, Nicolas MM, Greicius MD, Cramer SC, Breiter HC, Hasselmo ME, Stern CE. Blockade of central cholinergic receptors impairs new learning and increases proactive interference in a word paired-associate memory task. Behav Neurosci 2004;118:223-236. [PubMed: 14979800]

2. Hasselmo M, McGaughy J. High acetylcholine levels set circuit dynamics for attention and encoding and low acetylcholine levels set dynamics for consolidation. Progress in Brain Research 2004;145:207-231. [PubMed: 14650918]

3. Green A, Ellis KA, Ellis J, Bartholomeusz CF, Ilic S, Croft RJ, Luan Phan K, Nathan PJ. Muscarinic and nicotinic receptor modulation of object and spatial n-back working memory in humans. Pharmacol Biochem Behav 2005;81:575-584. [PubMed: 15936063]

4. Buccafusco JJ, Letchworth SR, Bencherif M, Lippiello PM. Long-lasting cognitive improvement with nicotinic receptor agonists: mechanisms of pharmacokinetic-pharmacodynamic discordance. Trends Pharmacol Sci 2005;26:352-360. [PubMed: 15946748]

5. Levin ED, McClernon FJ, Rezvani AH. Nicotinic effects on cognitive function: behavioral characterization, pharmacological specification, and anatomic localization. Psychopharmacology (Berl) 2006;184:523-539. [PubMed: 16220335]

6. Tang Y, Mishkin M, Aigner TG. Effects of muscarinic blockade in perirhinal cortex during visual recognition. Proc. Natl. Acad. Sci. USA 1997;94:12667-12669. [PubMed: 9356507]

7. Winters BD, Bussey TJ. Removal of cholinergic input to perirhinal cortex disrupts object recognition but not spatial working memory in the rat. Eur J Neurosci 2005;21:2263-2270. [PubMed: 15869523]

8. Blokland A, Honig W, Raaijmakers WGM. Effects of intra-hippocampal scopolamine injections in a repeated spatial acquisition task in the rat. Psychopharmacology 1992;109:373-376. [PubMed: 1365638]

9. Elvander E, Schott PA, Sandin J, Bjelke B, Kehr J, Yoshitake T, Ogren SO. Intraseptal muscarinic ligands and galanin: influence on hippocampal acetylcholine and cognition. Neuroscience 2004;126:541-557. [PubMed: 15183504]

10. Bunce JG, Sabolek HR, Chrobak JJ. Intraseptal infusion of the cholinergic agonist carbachol impairs delayed-non-match-to-sample radial arm maze performance in the rat. Hippocampus 2004;14:450459. [PubMed: 15224982]

11. Rogers JL, Kesner RP. Cholinergic modulation of the hippocampus during encoding and retrieval. Neurobiol Learn Mem 2003;80:332-342. [PubMed: 14521875]

12. McGaughy J, Koene RA, Eichenbaum H, Hasselmo ME. Cholinergic deafferentation of the entorhinal cortex in rats impairs encoding of novel but not familiar stimuli in a delayed non-match to sample task (DNMS). J. Neurosci 2005;25:10273-10281. [PubMed: 16267235]

13. Turchi J, Saunders RC, Mishkin M. Effects of cholinergic deafferentation of the rhinal cortex on visual recognition memory in monkeys. Proc Natl Acad Sci U S A 2005;102:2158-2161. [PubMed: 15684066]

14. Pang KC, Nocera R. Interactions between 192-IgG saporin and intraseptal cholinergic and GABAergic drugs: role of cholinergic medial septal neurons in spatial working memory. Behav Neurosci 1999;113:265-275. [PubMed: 10357451]

15. Giocomo LM, Hasselmo ME. Nicotinic modulation of glutamatergic synaptic transmission in region CA3 of the hippocampus. Eur J Neurosci 2005;22:1349-1356. [PubMed: 16190890] 
16. Radcliffe KA, Fisher JL, Gray R, Dani JA. Nicotinic modulation of glutamate and GABA synaptic transmission of hippocampal neurons. Ann N Y Acad Sci 1999;30:591-610. [PubMed: 10414340]

17. Gil Z, Conners BW, Amitai Y. Differential regulation of neocortical synapses by neuromodulators and activity. Neuron 1997;19:679-686. [PubMed: 9331357]

18. Gioanni Y, Rougeot C, Clarke PB, Lepouse C, Thierry AM, Vidal C. Nicotinic receptors in the rat prefrontal cortex: increase in glutamate release and facilitation of mediodorsal thalamo-cortical transmission. Eur J Neurosci 1999;11:18-30. [PubMed: 9987008]

19. Patil MM, Hasselmo ME. Modulation of inhibitory synaptic potentials in the piriform cortex. $J$ Neurophysiol 1999;81:2103-2118. [PubMed: 10322052]

20. Hasselmo ME, Schnell E. Laminar selectivity of the cholinergic suppression of synaptic transmission in rat hippocampal region CA1: computational modeling and brain slice physiology. J Neurosci 1994;14:3898-3914. [PubMed: 8207494]

21. Hasselmo ME, Bower JM. Cholinergic suppression specific to intrinsic not bafferent fiber synapses in rat piriform (olfactory) cortex. J. Neurophysiol 1992;67:1222-1229. [PubMed: 1597708]

22. Hasselmo ME, Schnell E, Barkai E. Dynamics of learning and recall at excitatory recurrent synapses and cholinergic modulation in rat hippocampal region CA3. J Neurosci 1995;15:5249-5262. [PubMed: 7623149]

23. Vogt KE, Regehr WG. Cholinergic modulation of excitatory synaptic transmission in the CA3 area of the hippocampus. J Neurosci 2001;21:75-83. [PubMed: 11150322]

24. Fernandez de Sevilla D, Buno W. Presynaptic inhibition of Schaffer collateral synapses by stimulation of hippocampal cholinergic afferent fibres. Eur J Neurosci 2003;17:555-558. [PubMed: 12581173]

25. de Sevilla DF, Cabezas C, de Prada AN, Sanchez-Jimenez A, Buno W. Selective muscarinic regulation of functional glutamatergic Schaffer collateral synapses in rat CA1 pyramidal neurons. J Physiol 2002;545:51-63. [PubMed: 12433949]

26. Linster C, Maloney M, Patil M, Hasselmo ME. Enhanced cholinergic suppression of previously strengthened synapses enables the formation of self-organized representations in olfactory cortex. Neurobiol Learn Mem 2003;80:302-314. [PubMed: 14521872]

27. Weinberger NM. The nucleus basalis and memory codes: auditory cortical plasticity and the induction of specific, associative behavioral memory. Neurobiology of Learning and Memory 2003;80:268284. [PubMed: 14521869]

28. Brazhnik ES, Muller RU, Fox SE. Muscarinic blockade slows and degrades the location-specific firing of hippocampal pyramidal cells. J Neurosci 2003;23:611-621. [PubMed: 12533621]

29. Kunitake A, Kunitake T, Stewart M. Differential modulation by carbachol of four separate excitatory afferent systems to the rat subiculum in vitro. Hippocampus 2004;14:986-999. [PubMed: 15390173]

30. Hasselmo ME. Neuromodulation: acetylcholine and memory consolidation. Trends Cogn Sci 1999;3:351-359. [PubMed: 10461198]

31. Chrobak JJ, Buzsaki G. Selective activation of deep layer (V-VI) retrohippocampal cortical neurons during hippocampal sharp waves in the behaving rat. J. Neurosci 1994;14:6160-6170. [PubMed: 7931570]

32. Gais S, Born J. Low acetylcholine during slow-wave sleep is critical for declarative memory consolidation. Proc Natl Acad Sci U S A 2004;101:2140-2144. [PubMed: 14766981]

33. Hasselmo ME, Cekic M. Suppression of synaptic transmission may allow combination of associative feedback and self-organizing feedforward connections in the neocortex. Behav Brain Res 1996;79:153-161. [PubMed: 8883827]

34. Metherate R, Hsieh CY. Synaptic mechanisms and cholinergic regulation in auditory cortex. Prog Brain Res 2004;145:143-156. [PubMed: 14650913]

35. Kimura F. Cholinergic modulation of cortical function: a hypothetical role in shifting the dynamics in cortical network. Neurosci Res 2000;38:19-26. [PubMed: 10997574]

36. Siok CJ, Rogers JA, Kocsis B, Hajos M. Activation of alpha7 acetylcholine receptors augments stimulation-induced hippocampal theta oscillation. Eur J Neurosci 2006;23:570-574. [PubMed: 16420464]

37. Bland BH, Oddie SD. Theta band oscillation and synchrony in the hippocampal formation and associated structures: the case for its role in sensorimotor integration. Behav Brain Res 2001;127:119-136. [PubMed: 11718888] 
38. Griffin AL, Asaka Y, Darling RD, Berry SD. Theta-contingent trial presentation accelerates learning rate and enhances hippocampal plasticity during trace eyeblink conditioning. Behav Neurosci 2004;118:403-411. [PubMed: 15113267]

39. Hasselmo ME, Bodelon C, Wyble BP. A proposed function for hippocampal theta rhythm: separate phases of encoding and retrieval enhance reversal of prior learning. Neural Comput 2002;14:793817. [PubMed: 11936962]

40. Yoder RM, Pang KC. Involvement of GABAergic and cholinergic medial septal neurons in hippocampal theta rhythm. Hippocampus 2005;15:381-392. [PubMed: 15630696]

41. Brazhnik ES, Fox SE. Action potentials and relations to the theta rhythm of medial septal neurons in vivo. Exp Brain Res 1999;127:244-258. [PubMed: 10452212]

42. Klausberger T, Magill PJ, Marton LF, Roberts JD, Cobden PM, Buzsaki G, Somogyi P. Brain-stateand cell-type-specific firing of hippocampal interneurons in vivo. Nature 2003;421:844-848. [PubMed: 12594513]

43. Chapman CA, Lacaille JC. Cholinergic induction of theta-frequency oscillations in hippocampal inhibitory interneurons and pacing of pyramidal cell firing. J Neurosci 1999;19:8637-8645. [PubMed: 10493764]

44. McQuiston AR, Madison DV. Muscarinic receptor activity has multiple effects on the resting membrane potentials of CA1 hippocampal interneurons. J Neurosci 1999;19:5693-5702. [PubMed: 10407010]

45. Alkondon M, Albuquerque EX. Nicotinic acetylcholine receptor alpha7 and alpha4beta2 subtypes differentially control GABAergic input to CA1 neurons in rat hippocampus. J Neurophysiol 2001;86:3043-3055. [PubMed: 11731559]

46. Pitler TA, Alger BE. Cholinergic excitation of GABAergic interneurons in the rat hippocampal slice. Journal of Physiology 1992;450:127-142. [PubMed: 1359121]

47. Lawrence JJ, Statland JM, Grinspan ZM, McBain CJ. Cell type-specific dependence of muscarinic signalling in mouse hippocampal stratum oriens interneurones. J Physiol 2006;570:595-610. [PubMed: 16322052]

48. Kunec S, Hasselmo ME, Kopell N. Encoding and retrieval in the CA3 region of the hippocampus: a model of theta-phase separation. J Neurophysiol 2005;94:70-82. [PubMed: 15728768]

49. Klink R, Alonso A. Muscarinic modulation of the oscillatory and repetitive firing properties of entorhinal cortex layer II neurons. J. Neurophysiol 1997;77:1813-1828. [PubMed: 9114238]

50. Fransen E, Tahvildari B, Egorov AV, Hasselmo ME, Alonso AA. Mechanism of graded persistent cellular activity of entorhinal cortex layer v neurons. Neuron 2006;49:735-746. [PubMed: 16504948]

51. Haj-Dahmane S, Andrade R. Ionic mechanism of the slow afterdepolarization induced by muscarinic receptor activation in rat prefrontal cortex. J. Neurophysiol 1998;80:1197-1210. [PubMed: 9744932]

52. Fransén E, Alonso AA, Hasselmo ME. Simulations of the role of the muscarinicactivated calciumsensitive nonspecific cation current INCM in entorhinal neuronal activity during delayed matching tasks. J Neurosci 2002;22:1081-1097. [PubMed: 11826137]

53. Young BJ, Otto T, Fox GD, Eichenbaum H. Memory representation within the parahippocampal region. J. Neurosci 1997;17:5183-5195. [PubMed: 9185556]

54. Suzuki WA, Miller EK, Desimone R. Object and place memory in the macaque entorhinal cortex. Neuroreport 1997;7:2231-2235.

55. Schon K, Atri A, Hasselmo ME, Tricarico MD, LoPresti ML, Stern CE. Scopolamine reduces persistent activity related to long-term encoding in the parahippocampal gyrus during delayed matching in humans. J Neurosci 2005;25:9112-9123. [PubMed: 16207870]

56. Olson IR, Sledge Moore K, Stark M, Chatterjee A. Visual working memory is impaired when the medial temporal lobe is damaged. J. Cogn. Neurosci 2006;18:1087-1097. [PubMed: 16839283]

57. Huerta PT, Lisman JE. Bidirectional synaptic plasticity induced by a single burst during cholinergic theta oscillation in CA1 in vitro. Neuron 1995;15:1053-1063. [PubMed: 7576649]

58. Adams SV, Winterer J, Muller W. Muscarinic signaling is required for spike-pairing induction of long-term potentiation at rat Schaffer collateral-CA1 synapses. Hippocampus 2004;14:413-416. [PubMed: 15224978] 
59. Cheong MY, Yun SH, Mook-Jung I, Joo I, Huh K, Jung MW. Cholinergic modulation of synaptic physiology in deep layer entorhinal cortex of the rat. J Neurosci Res 2001;66:117-121. [PubMed: 11599008]

60. Patil MM, Linster C, Lubenov E, Hasselmo ME. Cholinergic agonist carbachol enables associative long-term potentiation in piriform cortex slices. J Neurophysiol 1998;80:2467-2474. [PubMed: 9819256]

61. Ovsepian SV, Anwyl R, Rowan MJ. Endogenous acetylcholine lowers the threshold for long-term potentiation induction in the CA1 area through muscarinic receptor activation: in vivo study. Eur J Neurosci 2004;20:1267-1275. [PubMed: 15341598]

62. Leung LS, Shen B, Rajakumar N, Ma J. Cholinergic activity enhances hippocampal long-term potentiation in CA1 during walking in rats. J Neurosci 2003;23:9297-9304. [PubMed: 14561856] 


\section{High ACh \\ Low ACh}

\section{Input}

Input

\section{Nicotinic enhancement}

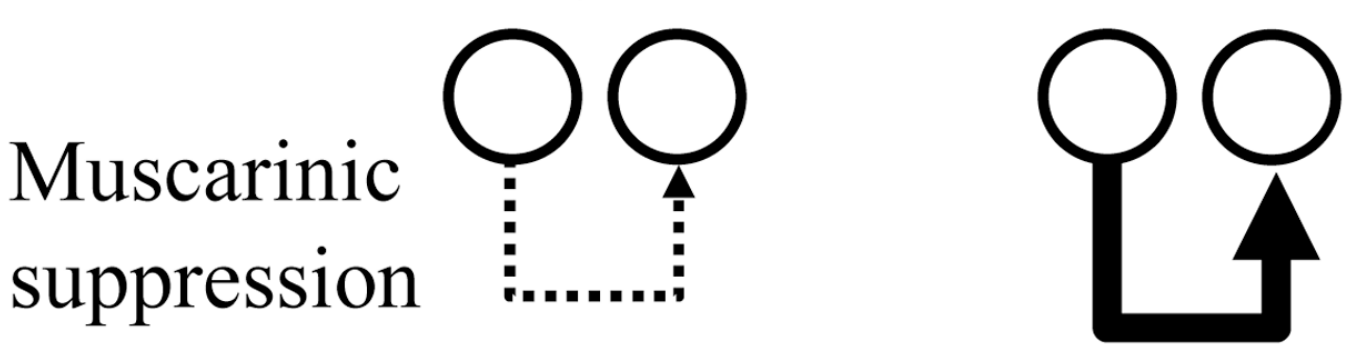

Feedback

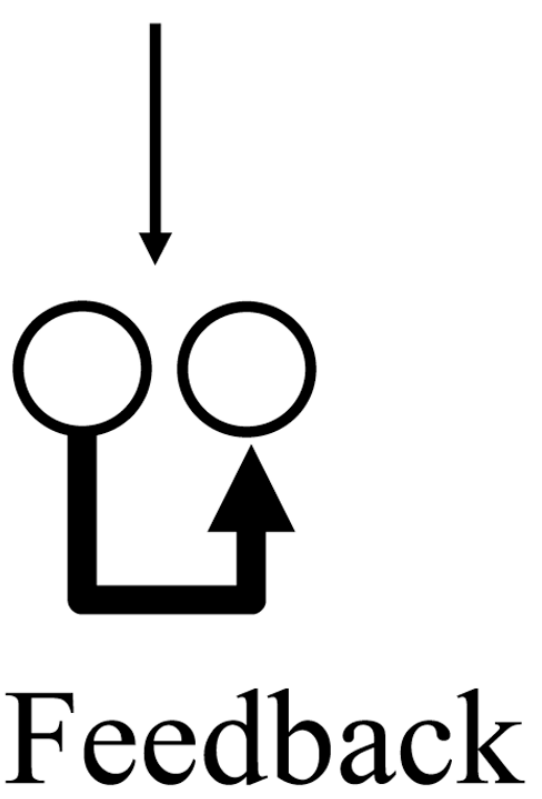

Figure 1.

Effect of acetylcholine on cortical dynamics. Left: High acetylcholine (ACh) levels enhance the magnitude of afferent input to cortex through action at nicotinic receptors. High ACh also suppresses the magnitude of feedback excitation in cortex via presynaptic inhibition of glutamate release. Right: Low acetylcholine levels result in a weaker influence of afferent input relative to the strength of excitatory feedback. 


\section{Encoding}
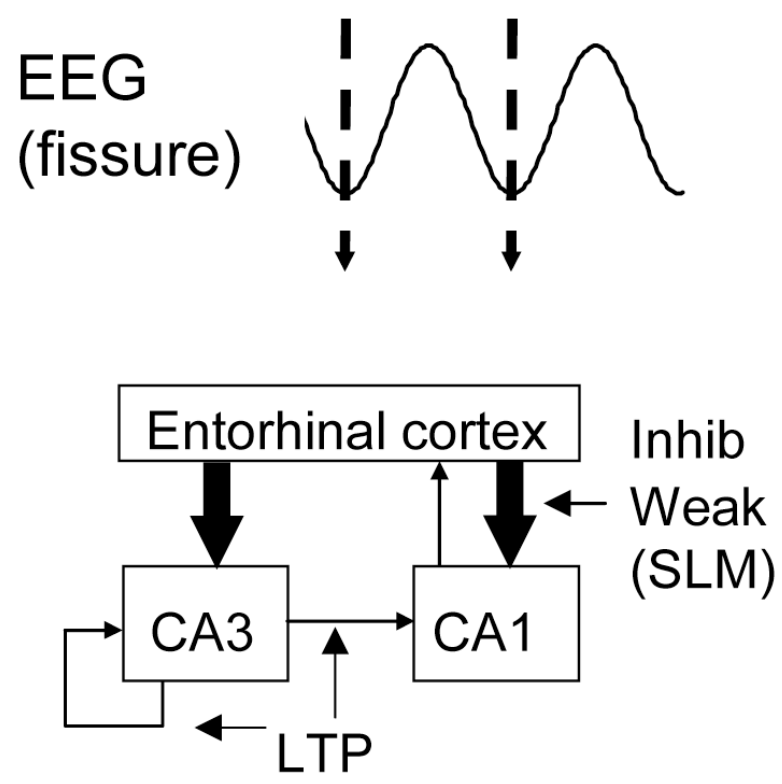

Retrieval
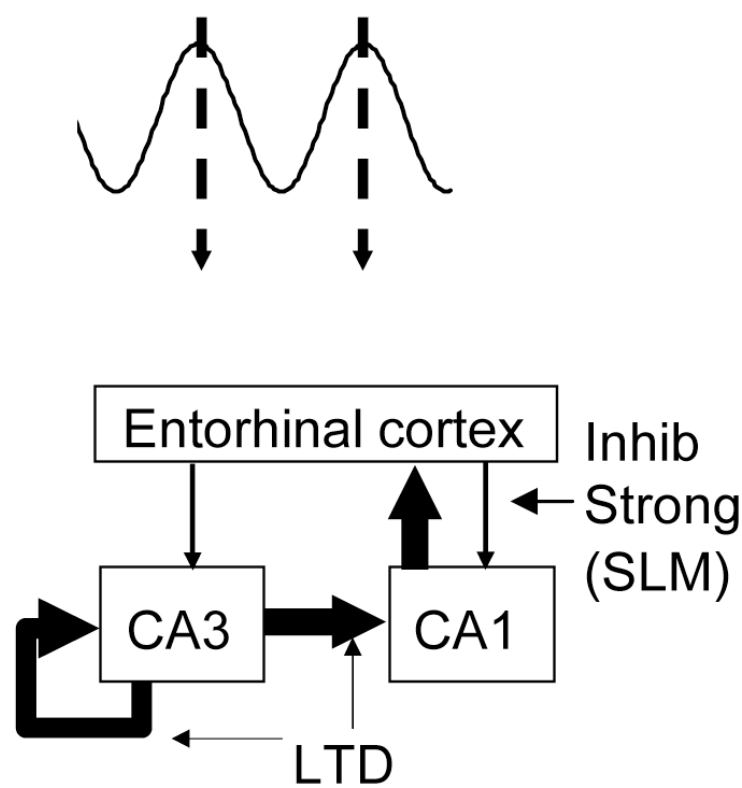

Figure 2.

Schematic of functional dynamics during theta rhythm. Modeling [39] suggests that encoding occurs at the trough and rising slope of theta, when current sinks are strong in stratum lacunosum-moleculare (SLM), where entorhinal input terminates, and currents in layers receiving CA3 input are weak. Retrieval would occur near the peak and falling slope of theta, when current sinks in SLM are weak and sinks in layers receiving CA3 input are strong.

Selective cholinergic modulation of SLM interneurons [43] and oriens-lacunosum-moleculare (OLM) cells [47] could selectively regulate inhibition of entorhinal input from weak to strong during different phases of theta. 


\section{Sample \\ Delay \\ Test \\ $\square$ \\ $\downarrow \downarrow \downarrow \downarrow$ \\ $\downarrow \downarrow \downarrow \downarrow \downarrow$ \\ Control
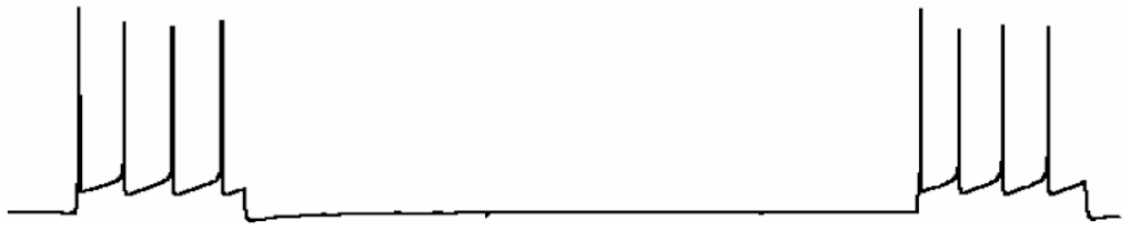 \\ High \\ $\mathrm{ACh}$

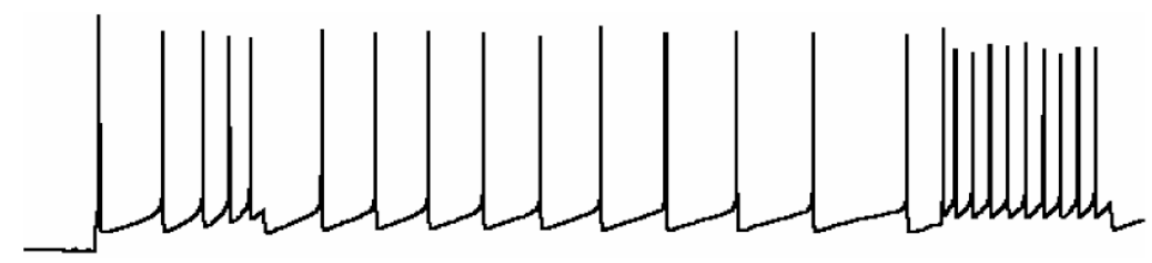

Figure 3.

Model of how acetylcholine induces persistent activity during the delay period of a delayed match to sample task. Top: In control conditions, a neuron responds to depolarizing input representing sample and test by spiking only during the depolarization. Bottom: Muscarinic cholinergic activation (High ACh) of intrinsic mechanisms allows persistent spiking to continue after the sample stimulus, resulting in spiking during the delay period for active maintenance of the stimulus, and causing greater spiking response during the matching test stimulus.

Green - **Study showing that systemic administration of scopolamine causes an impairment in working memory during a delayed matching task.

Winters - *Local infusion of scopolamine impairs spontaneous recognition of novel objects in rats.

Bunce - **Septal infusion of carbachol after initial trials causes impairments of memory for visited arms after a delay. This could be due to acetylcholine interfering with consolidation. McGaughy - **Selective lesions of the cholinergic innervation of entorhinal cortex selectively interferes with maintenance and encoding of novel odors for delayed matching, suggesting the loss of intrinsic mechanisms of persistent spiking, while not impairing delayed matching for familiar odors, suggesting that synaptic mechanisms can take over for inducing persistent spiking.

Turchi - **Selective lesions of cholinergic innervation of perirhinal cortex interfere with encoding of novel visual stimuli for subsequent recognition after a delay.

Giocomo - *Nicotinic modulation enhances excitatory transmission at entorhinal input to region $\mathrm{CA} 3$ of the hippocampus in stratum lacunosum-moleculare, but does not enhance recurrent excitatory transmission in stratum radiatum. 
De Sevilla - *Cholinergic presynaptic inhibition of synaptic transmission affects functional AMPA synapses, but does not affect NMDA currents at "silent synapses."

Gais - **The theory that low levels of acetylcholine are necessary for consolidation is supported by data showing that administration of the acetylcholinesterase blocker physostigmine after training (but before sleep) causes an impairment in memory function after sleep, possibly due to reduction of consolidation.

Griffin - *Demonstration that learning is enhanced when stimuli for conditioning are presented during periods of time in which theta rhythm has been detected, compared to slower learning during periods without theta rhythm.

Fransen - *Detailed computational modeling demonstrating a potential mechanism for graded persistent spiking activity, in which stability is obtained with a neutral zone in which cation currents do not change, between a high and a low threshold which induces changes in cation current.

Olson - *Demonstration that medial temporal lobe structures may be involved in working memory for complex novel stimuli, in addition to encoding into long-term memory. This working memory may depend on persistent spiking.

Ovsepian - *Demonstration that activation of cholinergic receptors in vivo enhances the induction of long-term potentiation. 